\title{
Choice of Future Career amongst Medical Students in Enugu, Nigeria: Implications for Anaesthesia
}

\author{
TC Onyeka \\ NP Ewuzie ${ }^{2}$ \\ Department of Anaesthesia ${ }^{1}$ \\ University of Nigeria Teaching \\ Hospital \\ Ituku-Ozalla Enugu, \\ Nigeria \\ Birmingham Heartlands \\ Hospital Birmingham, United \\ Kingdom $^{2}$

\section{All correspondence: \\ TC Onyeka} \\ Department of Anaesthesia \\ university of Nigeria Teaching \\ Hospital \\ Ituku-Ozalla Enugu, \\ Nigeria \\ E-mail: \\ doctortonia@yahoo.com
}

\begin{abstract}
\section{Background}

Despite its central role in modern healthcare delivery, anaesthesia has failed to attract adequate medical manpower in most developing countries. As a result, majority of anaesthetics are performed by non-physician practitioners.
\end{abstract}

\section{Objectives}

In this study, we examined the factors influencing choice of future career by medical student in Enugu, Nigeria and the implications for anaesthesia.

\section{Methods \\ We distributed questionnaires to medical students in the last two years of their training at the University of Nigeria, Enugu, asking them to indicate in order of priorities three specialties they will most likely consider for future career. They were also requested to state four most important factors influencing their choice.}

\section{Results}

All 195 completed forms were returned; 64\% were males and the average age of the respondents was 25.1 years. One hundred and eighty students $(93 \%)$ agreed to specialise, 1 did not while 12 were undecided. Only $1 \%$ of the students chose anaesthesia as their first choice. The other specialties like surgery (29\%), paediatrics (14\%), public health (14\%), obstetrics and gynaecology (12\%), radiology (11\%), internal medicine $(5 \%)$ and ophthalmology $(5 \%)$ were considerably of more interest to them. Ability to pursue other hobbies (40\%), academic and research opportunities (23\%), availability of training post (10\%), career progression (10\%), earning potential (9\%) and influence of a role model $(6 \%)$ were the factors affecting career decisions among the students.

\section{Conclusion}

This study has highlighted a very low level of interest for anaesthesia amongst Nigerian undergraduates. It also showed that ability to pursue other hobbies, availability of posts as well as academic and research opportunities are the main influencing factors in the choice of future specialty. We call for urgent measures be put in place to make anaesthesia more attractive to young medical graduates.

Key Words: Career Choice, Anaesthesia, Medical Students, Priorities.

\section{Introduction}

$\mathrm{T}$ here is an alarming lack of medical manpower in anaesthesia in the developing world despite its strategic role in modern medicine. This may be so because most young doctors in Nigeria do not consider a career in anaesthesia when embarking on residency training. ${ }^{1-5}$ This is even more troubling when one realizes that medical students are exposed to a wide range of medical subspecialties that includes anaesthesia, in the course of their medical education.

Some studies have also shown that pre-medical students (medical school entrants) have strong preferences for or against some subspecialties ${ }^{6}$.

Since the future workforce of our health-care systems are strongly influenced by the choices these students make, we looked at the factors that may influence medical students when making a career choice and the implications of these decisions on anaesthesia.

\section{Methods}

This study was conducted among fifth and final year students of the College of Medicine of the University of Nigeria, Enugu campus, in Enugu State, Nigeria. The questionnaire was administered to a total of 195 students (110 students in fifth year and 85 students in sixth year). The class representatives of the respective classes administered the questionnaires, collected them at their completion and submitted them to members of the study team. Response rate was $100 \%$. 
The questionnaire contained demographics, decision about specialization or not, and possible factors influencing their choice of career. Possible factors were selected following literature reviews and discussions with medical students and doctors. Demographic factors included age, sex and probable year of graduation. They were asked if they wanted to specialize or not. They were also asked three specialties they would most likely consider, ranking them in order of priority.

They were required to give four most important of twenty-one factors that influenced their decision. Specialty options included anaesthesia, community health, dental and maxillofacial surgery, family medicine, internal medicine, laboratory medicine(pathology), obstetrics and gynaecology, ophthalmology, otolaryngology, radiology, paediatrics, pharmacology and therapeutics, psychiatry and surgery. The options of 'undecided' and 'others' were included for those students who were yet to make up their minds and those who chose options outside those available in the questionnaire and outside the field of medicine, respectively.

Factors indicated in the questionnaire as influencing their choice of specialty were availability of training post, ability to pursue other hobbies, teaching/acadaemic opportunities, research opportunities, career progression, earning potentials and prior experience in the specialty. Others were prestige, family influence, and career opportunities, working hours during residency, influence of a role model/mentorship, doctor-patient relationship, intellectual stimulation and future patient demographics. Also included in the list were length of training required, gender distribution in the specialty, on-call schedule, lifestyle after training and working hours after training. Provision was also made for other factors which were not included in the questionnaire.

The Statistical Package for Social Sciences software (SPSS, version 11.5) was used to analyze the data. Differences in means were analyzed using independent sample t-test. Differences in proportions were analyzed using Chi-square test. A P-value of less than 0.05 was considered statistically significant.

\section{Results}

One hundred and ninety-fivecompleted forms were returned. The mean $(+/-\mathrm{SD})$ age of the respondents was $25.1+/-2.0 .125(64 \%)$ of them were males. One hundred and eighty students $(93 \%)$ wanted to specialise, 1 indicated no interest to specialise while $12(23 \%)$ were undecided. Only $1 \%$ of students considered anaesthesia as their first choice (Fig 1).
The most preferred specialty of first choice was surgery $(29 \%)$. Paediatrics and public health $(14 \%$ each) tied at second place while obstetrics and gynaecology (12\%) came in at third place. In the most preferred specialty of second choice, surgery (31\%) maintained the lead, paediatrics $(29 \%)$ was second and public health $(21 \%)$ was third. Anaesthesia (6\%) came in tenth place while others like dentistry/maxillofacial, haematology and oncology were at the bottom of the list. Surprisingly, one student chose a political career over a career in medicine.

When asked their specialty of third choice, public health $(27 \%)$ came in at first place, internal medicine $(23 \%)$ took the second place while paediatrics $(19 \%)$ was third. Surgery $(12 \%)$ was at sixth place and anaesthesia at tenth place, with $5 \%$ of medical students making it their preferred specialty. Concerning overall preference of specialty (obtained by merging first, second and third choices), surgery (19\%) was still in first place, with paediatrics (14\%) and public health (14\%) tied at second place while obstetric and gynaecology (11\%) found itself at third place. Anaesthesia (2\%) was in seventh place this time (Fig 2). Ability to pursue other hobbies (40\%), academic and research opportunities (23\%) were the leading factors affecting career decisions among the students. Others were availability of training post $(10 \%)$, career progression $(10 \%)$, earning potential $(9 \%)$ and influence of a role model $(6 \%)$.

Figure 1: Specialty of First Choice.

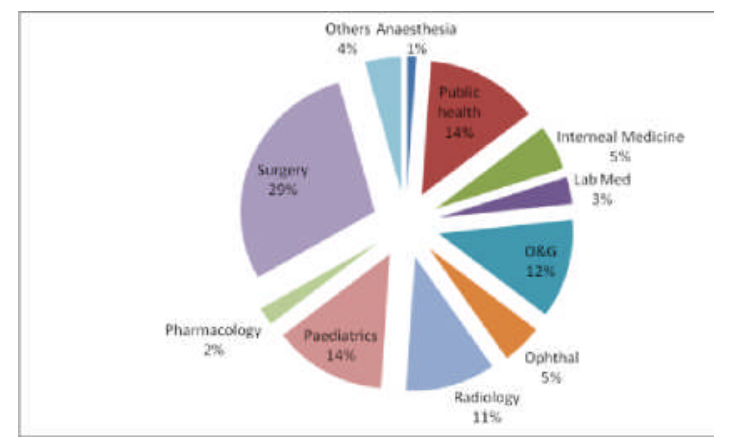

Figure 2: Overall Preference of Specialty.

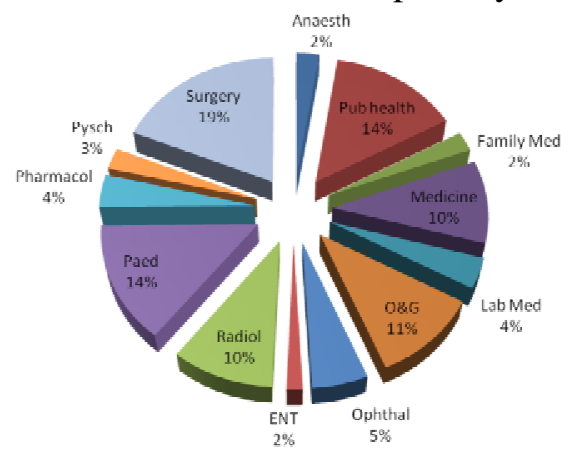




\section{Discussion}

This study agrees with previous reports, that there is a very low level of interest for anaesthesia amongst Nigerian undergraduates ${ }^{3,4,5}$. In the 80 s, none of 54 students selected anaesthesia as first choice; the specialty ranked sixth ${ }^{3}$. Of 67 final year medical students in another institution, $80 \%$ of them found anaesthesia interesting and important but none would pick anaesthesia as a first choice for future career. One-third of the students studied did not even consider it ${ }^{4}$. In Israel, just $1 \%$ of their medical graduates $^{7}$ and $5-6 \%$ of United States of America medical graduates choose anaesthesia. This is in stark contrast to $17.7 \%$ of Australian medical students intending to choose anaesthesia'. Two factors had the greatest influence on the choice made by the students: the ability to have time for their hobbies and academic/research opportunities. Others were training post, career progression, earning potentials and presence of a role model.

Anaesthesia is commonly taught to medical students but the duration and content of such teaching varies ${ }^{10}$. If these students receive a positive undergraduate experience by way of thorough teaching and lecturing, future recruitment into most disciplines of medicine including anaesthesia would be enhanced. One study showed that an intensive dedicated clerkship in oncology led to $25 \%$ of the medical students considering this branch of medicine ${ }^{11}$. In a survey of over 5000 new graduates, $45 \%$ of them were influenced in their career choice by the good exposure they had as undergraduates to the specialties, while $25 \%$ of them were influenced by a role model ${ }^{12}$. In another study, two-thirds of students identified a positive role model in their anaesthetic teachers and that this was significantly associated with a satisfactory learning experience and a career intention in anaesthesia ${ }^{9}$.

Many studies have suggested that there are areas that are often inadequately taught at undergraduate level ${ }^{13,14}$. In addition, short duration of exposure to anaesthesia, insufficient participation in practical anaesthesia and inadequate provision of teaching aids have been cited as contributory factors to the problem of limited interest or none-interest in anaesthesia. This has resulted in the diminishing of medical students' clinical skills in areas such as basic airway management, acute and chronic pain management and basic life support ${ }^{15}$. To circumvent this problem, some have recommended the detailed teaching of subspecialist areas to undergraduates ${ }^{10}$. It has also been suggested that those students who learn advanced anaesthetic skills are more likely to be interested in anaesthesia as a career". This underscores the fact that the students need to have mandatory clinical exposure during their training as this will help in the identification of interested and highly qualified students who will be encouraged to choose anaesthesia in future ${ }^{16}$. This would greatly improve the competence of newly-qualified doctors in our healthcare system.

One major implication of this trend for anaesthesia is a diminishing workforce. Currently, anesthesia has widened its spectrum of practice to involve diagnostic procedures for pediatric, radiology, gastroenterology and respiratory medicine patients, lithotripsy, dental surgery, palliative care, trauma treatment, resuscitation, emergency medicine, and transport of critically ill patients ${ }^{17}$. This is in addition to its classic role of providing the best and safest conditions for the performance of surgery following preoperative assessment, postoperative care in recovery rooms, obstetric analgesia (epidural) in delivery rooms and running the intensive care units, pain clinics and acute pain services ${ }^{18}$. Without high level manpower in anaesthesia, advancements in major areas of surgery would be stunted.

Increase in non-physician anaesthetist role is another implication for consideration. Successful surgery is dependent on the quality and safety of the anaesthesia provided. More critical incidents and anaesthetic deaths in this era of "Patient safety" would be alarming. Some associations such as the Israel Medical Association and the Israel Society of Anesthesiologists strongly believe that replacing physicians with technicians or nurses is a dangerous step that may cause deterioration in the level of practice and patient safety ${ }^{7}$. In the study of students in Jordanian university medical schools, none of the male students chose a career in anesthesia. This was attributed to the increase in the number of nurse anesthetists employed at university hospitals, which seemed to suggest to the students, a lack of career opportunities in this field ${ }^{6}$.

\section{Conclusion}

As our study data shows, the trend of lack of anaesthetists will continue into the next decade if the situation is not remedied. Because the content of teaching varies, there is need to ensure optimal exposure to the specialty in the undergraduate curriculum as well as unifying and standardizing the curriculum throughout the medical schools in the country. While other specialties are attractive to students prior to clinical exposure, some studies have shown that doctors rarely choose to enter into 
anesthesia until they have had some clinical experience $^{16}$. Therefore, teaching methods should be improved on and the course content made exciting for the medical students during their postings in anaesthesia. This could be achieved through the use of seminars, videos, computers, airway skills laboratory and anesthesia simulators.

Education on career opportunities and subspecialization in anaesthesia will also help many students in the modification of ill-advised choices previously made. During the 2009 Nigerian Society of Anaesthetists (NSA) Annual General Meeting, other suggestions made about sensitization of students to anaesthesia included the creation of an "Anaesthesia Day" as an annual event, public enlightenment programmes about the specialty through the mass media and wearing of special or distinct theatre outfits. Finally, quality interactions between faculty anaesthetists and the students as well as active involvement of senior anaesthetists in undergraduate training through motivational guidance and charismatic mentorship will go a long way to generating a new wave of interest in anaesthesia among medical students.

\section{References}

1. Karalliedde LD, Senanayake N, Aluwihare APR Young doctors' preferences in the third world. World Health Forum 1987; 8: 504-7.

2. Khan FA, Hamdani GA. Factors influencing the choice of anesthesia as a career in a developing country. Middle East J Anesthesiol 2007; 19: $149-58$.

3. Akinyemi OO, Soyannwo AO. The choice of anaesthesia as a career by undergraduates in a developing country. Anaesthesia 1980; 35: 712715 .

4. Faponle AF. Anaesthesia as a career--the influence of undergraduate education in a Nigerian Medical School. Nigeria Postgraduate Medical Journal 2002; 9: 11-2.

5. Ene EE, Akpan SG. Undergraduate teaching: a developing country experience. Anaesthesia 1982; 37: 10224 .

6. Khader Y, Al-Zoubi D, Amarin Z, Alkafagei A, Khasawneh M, Burgan S, et al. Factors affecting medical students in formulating their specialty preference in Jordan. BMC Med Ed 2008; 8: 32.
7. Goldik Z, Perel A. The impending crisis of anesthesiology in Israel. IMAJ 2006; 8: 280282.

8. Alexander LA, Miller JN. Anesthesiology in medical school reaching, teaching and recruiting students. Acad Med 1989; 64: 485.

9. Watts RW, Marley J, Worley P. Undergraduate education in anaesthesia: the influence of role models on skills learnt and career choice. Anaesth Int Care 1998; 26(2): 201 -203.

10. Alahlafi A, Burge S. What should undergraduate medical students know about psoriasis? Involving patients in curriculum development: modified Delphi technique. Br Med J 2005; 330: $633-636$.

11. Notzer N, Tur-Kaspa R. Medical students' reaction to their experiences in oncology and its contribution to their training. Harefuah 2006; 145: $32-35$.

12. Goldacre MJ, Turner G, Lambert TW. Variation by medical students in career choices of UK undergraduates of 1999 2000. Med Ed 2004; 38: 249-258.

13. Rohan D, Ahern S, Walsh K. Defining an anaesthetic curriculum for medical undergraduates in a Delphi study. Med Teacher 2009;31(1): e1 e5.

14. Morgan PJ, Cleave-Hogg D, DeSousa S, Taeshis J. Identification of gaps in the achievement of undergraduate anesthesia educational objectives using high-fidelity patient stimulation. Anesth Analg 2003; 97: 1690-1694.

15. Barnsley L, Lyon PM, Ralston SJ, Hibbert EJ, Cunningham I, Gordon FC, et al. Clinical skills in junior medical officers: a comparison of selfreported confidence and observed confidence. Med Ed 2004; 38: 358 -367.

16. Carvajal L, Graham M, Curry S. Experiential and motivational factors influencing the choice of anesthesiology as a career. Anesthesiology 2006; 105: A1320.

17. McGlennan A, Gold S, Cooper G. Anaesthesia. BrMed J Careers 2005;311:83-87.

18. Turner G, Goldacre MJ, Lambert Tw, Sears JW. Career choice for anaesthesia: national survey of graduates of 19742002 from UK medical schools. BJA 2005; 95(3): 332 -338. 